\title{
A feeding tube model for activation of a cell-specific transcription factor during sporulation in Bacillus subtilis
}

\author{
Amy H. Camp and Richard Losick ${ }^{1}$ \\ Department of Molecular and Cellular Biology, Harvard University, Cambridge, Massachustts 02138, USA
}

\begin{abstract}
Spore formation by Bacillus subtilis takes place in a sporangium consisting of two chambers, the forespore and the mother cell, which are linked by pathways of intercellular communication. One pathway, which couples the activation of the forespore transcription factor $\sigma^{\mathrm{G}}$ to the action of $\sigma^{\mathrm{E}}$ in the mother cell, has remained mysterious. Traditional models hold that $\sigma^{\mathrm{E}}$ initiates a signal transduction pathway that specifically activates $\sigma^{\mathrm{G}}$ in the forespore. Recent experiments indicating that the mother cell and forespore are joined by a channel have led to the suggestion that a specific regulator of $\sigma^{G}$ is transported from the mother cell into the forespore. As we report here, however, the requirement for the channel is not limited to $\sigma^{\mathrm{G}}$. Rather, it is also required for the persistent activity of the early-acting forespore transcription factor $\sigma^{\mathrm{F}}$ as well as that of a heterologous RNA polymerase (that of phage T7). We infer that macromolecular synthesis in the forespore becomes dependent on the channel at intermediate stages of development. We propose that the channel is a gap junction-like feeding tube through which the mother cell nurtures the developing spore by providing small molecules needed for biosynthetic activity, including $\boldsymbol{\sigma}^{\mathrm{G}}$-directed gene activation.
\end{abstract}

[Keywords: Bacillus subtilis; sporulation; cell-cell communication; feeding tube; gene regulation; $\sigma^{\mathrm{G}}$ ]

Supplemental material is available at http://www.genesdev.org.

Received January 14, 2009; revised version accepted March 11, 2009.

Both bacterial and eukaryotic cells communicate by the exchange of signaling molecules. Traditional mechanisms of intercellular signaling include the secretion and detection of soluble molecules that can act at a distance, as well as interactions between membranebound ligands and receptors of adjacent cells. Another more intimate type of communication involves stable intercellular bridges, channels, or tubules, which provide portals for the exchange of cytoplasmic materials from one cell to another (Robinson and Cooley 1996). In eukaryotic cells, small cell-to-cell channels known as gap junctions permit the passive transport of ions and small molecules, such as sugars, amino acids, and nucleotides (Kumar and Gilula 1996). Other larger types of intercellular bridges, such as the ring canals that link Drosophila nurse cells to the developing oocyte and the plasmodesmata that link plant cells, additionally permit the transfer of macromolecules such as RNAs and proteins (Robinson and Cooley 1996; Gallagher and Benfey 2005). Examples of direct intercellular transport of molecules can also be found for bacteria. In these cases, a specialized apparatus, the type III or type IV secretion

${ }^{1}$ Corresponding author.

E-MAIL losick@mcb.harvard.edu; FAX (617) 496-4642.

Article is online at http://www.genesdev.org/cgi/doi/10.1101/gad.1781709. channel, transfers specific DNA and/or protein molecules from a donor bacterium to the cytoplasm of a recipient bacterium or a eukaryotic host cell (Christie et al. 2005; Galan and Wolf-Watz 2006). However, no examples of contiguous cytoplasmic bridges analogous to gap junctions or plasmodesmata have been described in bacteria. Here we provide evidence for a gap-junction-like "feeding tube" that links the developing spore to its mother cell during differentiation in the bacterium Bacillus subtilis.

Spore formation takes place in a two-chamber sporangium that consists of a forespore, which will become the spore, and a mother cell (Fig. 1A). Initially, the forespore and the mother cell, which arise by asymmetric division, lie side by side. Next, at intermediate stages of spore formation, the forespore is engulfed by the mother cell to create a free protoplast within the mother cell cytoplasm. Gene expression in the two cells is principally governed by four cell-specific $\sigma$ factors: $\sigma^{\mathrm{E}}, \sigma^{\mathrm{F}}, \sigma^{\mathrm{G}}$, and $\sigma^{\mathrm{K}}$. The $\sigma^{\mathrm{F}}$ and $\sigma^{\mathrm{E}}$ factors direct gene expression in the forespore and mother cell, respectively, early in sporulation. Later, $\sigma^{\mathrm{G}}$ replaces $\sigma^{\mathrm{F}}$ in the forespore, and $\sigma^{\mathrm{K}}$ replaces $\sigma^{\mathrm{E}}$ in the mother cell. Importantly, three intercellular pathways link the activities of these $\sigma$ factors. First, a signal transduction pathway instigated by the action of $\sigma^{\mathrm{F}}$ in the forespore triggers the activation of $\sigma^{\mathrm{E}}$ in the mother cell. Next, $\sigma^{\mathrm{E}}$-directed gene expression causes $\sigma^{\mathrm{G}}$ activation in 
A

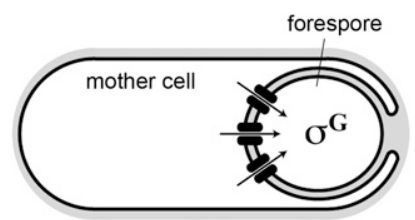

B

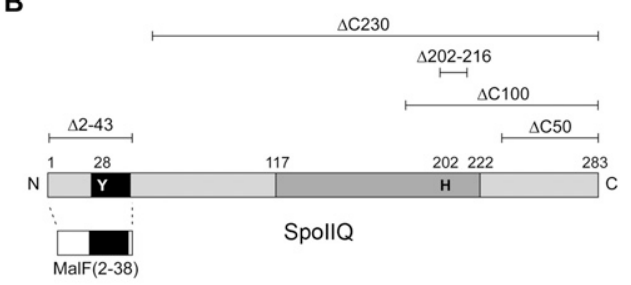

C

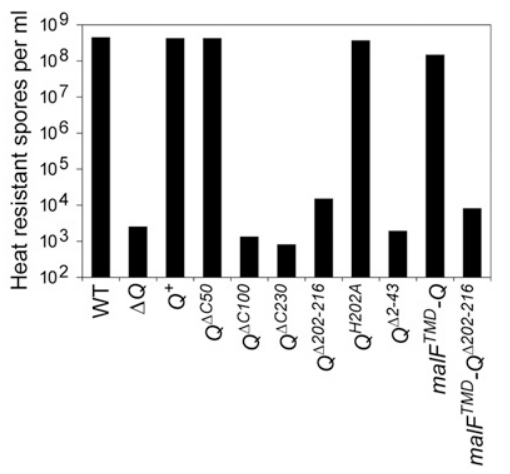

Figure 1. The sporangium, $\sigma^{\mathrm{G}}$, and the functional dissection of SpoIIQ. (A) Shown is a cartoon of the sporangium at the stage of engulfment when $\sigma^{\mathrm{G}}$ becomes active in the forespore. Also shown are channels composed of AA-AH and Q that are herein proposed to serve as feeding tubes between the mother cell and the forespore. $(B)$ Full-length $\mathrm{Q}$ and its truncated variants. Q harbors a short cytoplasmic $\mathrm{N}$ terminus ( $\sim 20$ residues), followed by a transmembrane domain (depicted as a black box), and a large extracellular C-terminal domain ( $\sim 240$ residues). The region (residues 117-222) that displays similarity to the M23 family of lysostaphin-like peptidases is shaded dark gray. Two highly conserved amino acids, Tyr28 and His202, are depicted as $\mathrm{Y}$ and $\mathrm{H}$, respectively. Shown below is the $\mathrm{N}$-terminal region of the E. coli protein MalF used to replace the $\mathrm{N}$-terminal region of $\mathrm{Q}$ to create the MalF ${ }^{\mathrm{TMD}}$-Q chimera; the MalF transmembrane domain is shown as a black box. (C) Heat-resistant spore formation by cells harboring mutant alleles of $Q$. With the exception of the parental strain harboring wild-type Q (WT), cells were deleted for the $Q$ gene $(\Delta Q)$ at its normal location or were deleted for $Q$ and harbored at $s a c A$ either wild-type $Q\left(Q^{+}\right)$ or the mutant alleles $Q^{\Delta C 50}, Q^{\Delta C 100}, Q^{\Delta C 230}, Q^{\Delta 202-216}, Q^{H 202 A}$, $Q^{\Delta 2-42}, m_{a l F^{T M D}}-Q$, or malF ${ }^{T M D}-Q^{\Delta 202-216}$ (strains PY79', AHB141, AHB1361, AHB1362, AHB1363, AHB1372, AHB1375, AHB1369, AHB1374, AHB1418, and AHB1533, respectively).

the forespore. Finally, $\sigma^{\mathrm{G}}$ sets in motion a signal transduction pathway that activates $\sigma^{\mathrm{K}}$ in the mother cell.

Whereas the signal transduction systems linking $\sigma^{\mathrm{F}}$ to $\sigma^{\mathrm{E}}$ and $\sigma^{\mathrm{G}}$ to $\sigma^{\mathrm{K}}$ are relatively well understood (for review, see Rudner and Losick 2001; Hilbert and Piggot 2004), the pathway tying the activity of $\sigma^{\mathrm{G}}$ in the forespore to the action of $\sigma^{\mathrm{E}}$ in the mother cell has remained mysterious. Activation of $\sigma^{\mathrm{G}}$ is known to require the eight protein products, SpoIIIAA-SpoIIIAH (henceforth AA-AH), of the spoIIIA operon, which is transcribed under the direction of $\sigma^{\mathrm{E}}$ in the mother cell (Illing and Errington 1991; Kellner et al. 1996; Guillot and Moran 2007), and the forespore protein SpoIIQ (henceforth Q), whose gene is transcribed by $\sigma^{\mathrm{F}}$ (Londoño-Vallejo et al. 1997; Sun et al. 2000). An important clue to how $\sigma^{\mathrm{E}}$ triggers the activation of $\sigma^{\mathrm{G}}$ comes from the evidence indicating that the AA-AH and $\mathrm{Q}$ proteins form a channel (henceforth the $\mathrm{AA}-\mathrm{AH} \cdot \mathrm{Q}$ channel) that connects the mother cell to the forespore (Camp and Losick 2008; Meisner et al. 2008). This evidence includes the similarity of $\mathrm{AH}$ to a multimerizing, pore-forming component of bacterial type III secretion channels (Camp and Losick 2008; Meisner et al. 2008), the ability of the AH and Q extracellular domains to interact in the space between the inner and outer forespore membranes (Blaylock et al. 2004; Doan et al. 2005), and the demonstration that the AH and Q extracellular domains are accessible from the forespore cytoplasm (Meisner et al. 2008).

Traditional models for the activation of $\sigma^{\mathrm{G}}$ posit that $\sigma^{\mathrm{E}}$-directed gene expression sets in motion a chain of events that specifically stimulates the activity of $\sigma^{\mathrm{G}}$ in the forespore or that counteracts the action of an inhibitor (e.g., an anti- $\sigma$ factor) of $\sigma^{\mathrm{G}}$. In keeping with this view, the discovery that the $\mathrm{AA}-\mathrm{AH}$ and $\mathrm{Q}$ proteins connect the mother cell to the forespore promoted the idea that the $\mathrm{AA}-\mathrm{AH} \cdot \mathrm{Q}$ channel is a conduit for the transport into the forespore of a $\sigma^{\mathrm{G}}$-specific regulatory protein (Meisner et al. 2008). Here, however, we argue against the idea of a specific regulatory protein. Instead, we report evidence indicating that general macromolecular synthesis in the forespore becomes dependent on the $\mathrm{AA}-\mathrm{AH} \bullet \mathrm{Q}$ channel at intermediate times of sporulation. According to our "feeding tube" model, the AA-AH and $Q$ proteins form a gap junction-like channel through which the mother cell nurtures the forespore by providing one or more small molecules generally required for macromolecular synthesis.

\section{Results}

A conserved domain of $Q$ is required for spore formation, $\sigma^{G}$ activation, and $A H$ localization

As a starting point for this investigation, we sought to identify regions of $\mathrm{Q}$ important for $\mathrm{AA}-\mathrm{AH} \bullet \mathrm{Q}$ channel function in $\sigma^{\mathrm{G}}$ activation and sporulation. Figure $1 \mathrm{~B}$ depicts the domain organization of the Q protein, which is produced in the forespore and anchored in the membrane via a single $\mathrm{N}$-terminal transmembrane domain. Only a small region near the $\mathrm{N}$ terminus of $\mathrm{Q} \quad(\sim 20$ residues) is present in the forespore cytoplasm. The larger C-terminal domain ( $\sim 240$ residues) of $Q$ is exposed to the extracellular space between the forespore and mother cell membranes (Londoño-Vallejo et al. 1997), where it interacts with the extracellular domain of the mother cell membrane protein AH (Blaylock et al. 2004; Doan et al. 2005). In particular, we reasoned that $Q$ variants that cannot interact with $\mathrm{AH}$ should disrupt channel 
assembly and/or function, and in turn block $\sigma^{\mathrm{G}}$ activation and spore formation.

To identify critical regions of $\mathrm{Q}$, we generated a progressive series of deletions from the $3^{\prime}$ end of $Q$ (Fig. 1B; data not shown). These deletion-mutated genes were placed under the control of the endogenous $Q$ promoter and were inserted at the nonessential sacA locus in cells deleted for the native $Q$ gene. A control strain harboring the wild-type $Q$ gene $\left(Q^{+}\right)$at sacA produced wild-type levels of spores (Fig. 1C). Likewise, $Q^{\Delta C 50}$ also supported wild-type levels of spore formation, indicating that the C-terminal 50 amino acids of Q (residues 234-283) are dispensable (Fig. 1C). In contrast, $Q^{\Delta C 100}$ and longer deletion mutants were blocked in sporulation, indicating that, at a minimum, the region between residues 184-233 is necessary for $\mathrm{Q}$ function (Fig. 1C; data not shown).

This essential region of $Q$ contains a block of 15 amino acids (His202-Pro216) that are conserved among Q orthologs from Bacilli (Supplemental Fig. S1). To test the importance of the His202-Pro216 region, we constructed an internal deletion in the $Q$ gene $\left(Q^{\Delta 202-216}\right.$; Fig. $1 \mathrm{~B}$; Supplemental Fig. S1). A strain expressing $Q^{\Delta 202-216}$ was defective for spore formation to almost the same extent as a strain deleted for $Q$ altogether (Fig. 1C). We also found that the His202-Pro216 residues were needed for $\sigma^{\mathrm{G}}$ activation. As shown in Figure 2A, cells harboring $Q^{\Delta 202-216}$, like those deleted for $Q$ altogether, displayed significantly reduced expression of a lacZ reporter gene fused to a promoter $\left(\mathrm{P}_{\text {ssp }}\right)$ under the exclusive control of $\sigma^{\mathrm{G}}$ (Sun et al. 1991). In comparison, control $Q^{+}$cells activated $\sigma^{\mathrm{G}}$ with the same timing (commencing $\sim 3-4 \mathrm{~h}$ after the onset of sporulation) and to the same levels as seen in an otherwise wild-type strain (Fig. 2A; data not shown).

Finally, we tested the importance of Q residues His202Pro216 for localization of the mother cell protein AH. The extracellular domains of $\mathrm{Q}$ and $\mathrm{AH}$ interact in the space between the forespore and mother cell, likely mediating $\mathrm{AA}-\mathrm{AH} \cdot \mathrm{Q}$ channel assembly, and this interaction is required for the proper localization of $\mathrm{AH}$ (Blaylock et al. 2004; Doan et al. 2005). To monitor AH localization, we constructed a strain harboring a fusion of the green fluorescent protein (GFP) to the $\mathrm{N}$ terminus of $\mathrm{AH}$. The $g f p-A H$ gene fusion was expressed under the control of a promoter internal to the spoIIIA operon $\left(\mathrm{P} 2_{\text {spoIIIA }}\right)$ that is necessary and sufficient for full levels of $A H$ expression (Guillot and Moran 2007). The $\mathrm{P} 2_{\text {spoIIIA }}-g f p-A H$ construct supported nearly wild-type levels of spore formation, indicating that the GFP-AH fusion protein was functional (data not shown). Consistent with previous reports (Blaylock et al. 2004; Doan et al. 2005), we found that GFP-AH localized to the engulfing septal membrane of the mother cell and, once forespore engulfment was complete, to the outer forespore membrane (which is derived from the engulfing mother cell membrane) (Fig. $2 \mathrm{C})$. We also occasionally observed, as reported in the aforementioned studies, uneven or punctate GFP-AH localization around the forespore, which we speculate may correspond to sites of AA-AH・Q channels (Fig. 2C, arrowheads). As expected, GFP-AH became mislocalized
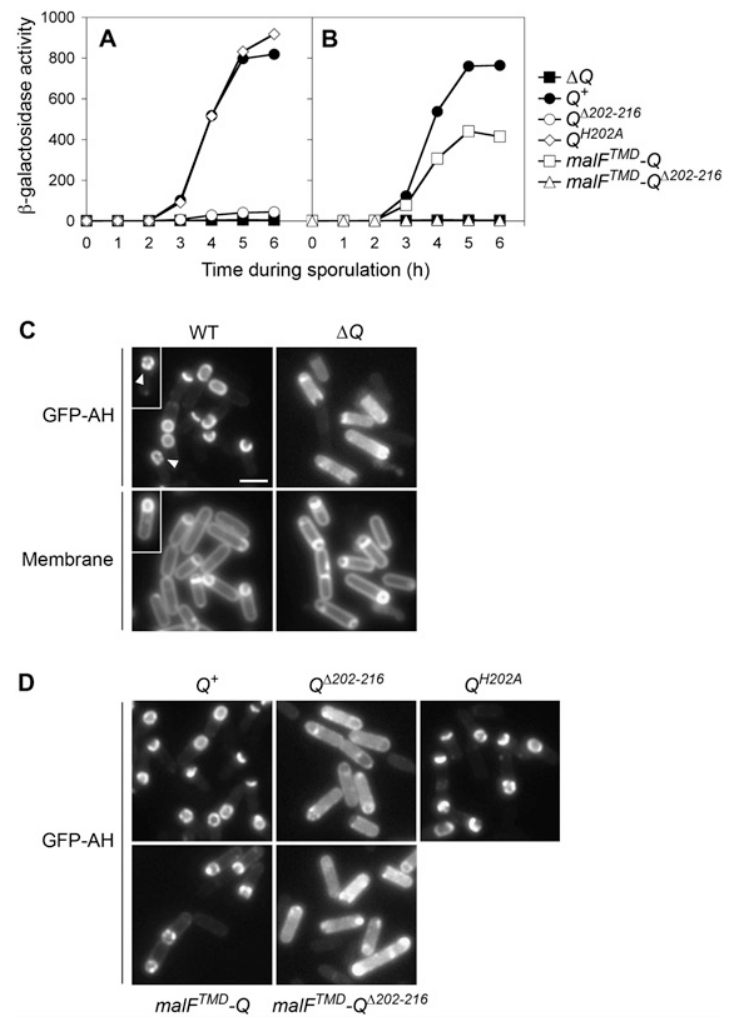

Figure 2. $\sigma^{\mathrm{G}}$ activity and $\mathrm{AH}$ localization in cells producing mutant $\mathrm{Q}$ proteins. $(A, B) \sigma^{\mathrm{G}}$ activity in strains harboring mutant $Q$ alleles. $\sigma^{\mathrm{G}}$-dependent expression of a $\mathrm{P}_{\text {ssp }}$-lac $Z$ fusion inserted at the $y w r K$ locus was monitored during sporulation of strains deleted for $Q(\Delta Q$; closed squares) or deleted for $Q$ and harboring either $Q^{+}$(closed circles), $Q^{\Delta 202-216}$ (open circles), $Q^{H 202 A}$ (open diamonds), malF ${ }^{T M D}-Q$ (open squares), or malF $F^{T M D}-Q^{\Delta 202-216}$ (open triangles) at the sacA locus (strains AHB1399, AHB1401, AHB1408, AHB1405, AHB1537, and AHB1538, respectively). For clarity, $Q^{\Delta 202-216}$ and $Q^{H 202 A}$ data are shown in $A$, while $m a l F^{T M D}-Q$ and $\operatorname{malF}^{T M D}-Q^{\Delta 202-216}$ data are shown in $B$. $\beta$-Galactosidase production in $Q$ deletion and $Q^{+}$control strains measured for each experiment is shown for comparison. $(C, D)$ Localization of $\mathrm{AH}$ in cells producing mutant $\mathrm{Q}$ proteins. In each strain, the native $A H$ gene was deleted and a functional $g f p-A H$ fusion was inserted at the $a m y E$ locus. $(C)$ GFP-AH fluorescence in wild-type cells (WT; strain AHB1508) or cells deleted for $Q(\Delta Q$; strain AHB1516) at hour 3 of sporulation. Arrowheads indicate wild-type cells that display uneven or punctate GFP-AH localization. Inset cell exemplifies the punctate GFP-AH localization seen in a subset of cells. Bar, $2 \mu \mathrm{m}$. Membrane fluorescence from FM 4-64 staining for each corresponding field is also shown below. Membranes of engulfed forespores are not visible due to the membrane impermeability of the FM 4-64 dye. (D) GFP-AH localization at sporulation hour 3 in cells deleted for the endogenous $Q$ gene and expressing either $Q^{+}, Q^{\Delta 202-216}, Q^{H 202 A}$, malF $^{T M D}-Q$, or malF $F^{T M D}-Q^{\Delta 202-216}$ from the sacA locus (strains AHB1527, AHB1531, AHB1552, and AHB1532, AHB1555, respectively).

to the mother cell cytoplasm in a $Q$ deletion strain (Fig. 2C; Blaylock et al. 2004; Doan et al. 2005). Strikingly, we found that GFP-AH was likewise mislocalized in cells harboring $Q^{\Delta 202-216}$ (Fig. 2D), indicating that $\mathrm{Q}$ residues 
His202-Pro216 are important for proper AH localization. We infer that the His202-Pro216 region of Q is directly or indirectly required for the assembly of the channel, and hence for $\sigma^{\mathrm{G}}$ activity and spore formation.

His202 is not required for Q-mediated spore formation, $\sigma^{G}$ activation, or AH localization

A large segment of the $\mathrm{Q}$ extracellular domain (residues 117-222) displays similarity to a family of zinc metallopeptidases that includes lysostaphin from Staphlococci (Pfam "Peptidase_M23" family; Fig. 1B; Supplemental Fig. S1), as has been previously noted (Londoño-Vallejo et al. 1997; Smith et al. 2000; Sun et al. 2000). The Q proteins from Bacilli have maintained the presumed catalytic histidine residue (His202 in B. subtilis Q) as well as two of the three amino acid residues that coordinate a zinc ion $\left(\mathrm{Zn}^{2+}\right)$ (Asp123 and His204 in B. subtilis Q) (Gustin et al. 1996; Odintsov et al. 2004; Firczuk et al. 2005; Ragumani et al. 2008; Rawlings et al. 2008). Interestingly, His202-Pro216 lie within this lysostaphin-like region and harbor the presumed catalytic histidine residue (His202) and one of the potential $\mathrm{Zn}^{2+}$ coordinating residues (His204). To investigate the significance of this, we switched the codon for His202 to an alanine codon. However, a strain harboring $Q^{H 202 A}$ produced wild-type levels of heat-resistant spores (Fig. 1C) and was unimpaired in $\sigma^{\mathrm{G}}$ activity (Fig. 2A) and GFP-AH localization (Fig. 2D). Likewise, a mutant $\mathrm{Q}$ in which His202 and the potential $\mathrm{Zn}^{2+}$-coordinating residues Asp123 and His204 (as well as Ser119) (see Supplemental Fig. S1) were simultaneously substituted for alanine was similarly unimpaired (data not shown). These data indicate that $\mathrm{Q}$ does not act as a peptidase, or if so, that this activity does not rely on His202 (or Ser119, Asp123, or His204) and/or is not critical for Q function. Instead, and in toto, the results are consistent with the idea that residues His202-Pro216 function in the assembly of the $\mathrm{AA}-\mathrm{AH} \cdot \mathrm{Q}$ channel, probably as a direct contact site between $\mathrm{Q}$ and $\mathrm{AH}$.

The Q extracellular domain is sufficient for spore formation, $\sigma^{G}$ activation, and AH localization

We next investigated the importance of the short $\mathrm{N}$-terminal cytoplasmic region and single-pass in $\rightarrow$ out transmembrane domain (TMD) (Fig. 1B) of Q for its function(s) during sporulation. To test the requirement for the $\mathrm{Q} T \mathrm{TMD}$, we generated a $Q$ deletion mutant lacking codons 2-43, which encode the $\mathrm{N}$-terminal cytoplasmic domain and TMD $\left(Q^{\Delta 2-43}\right)$ (Fig. 1B). As expected, $Q^{\Delta 2-43}$ was unable to support spore formation (Fig. 1C), indicating that, at the very least, the membrane topology of $\mathrm{Q}$ imparted by the TMD is critical for its function(s).

To determine whether the $\mathrm{Q} \mathrm{N}$-terminal domain and/ or TMD play any specific role beyond governing the proper topology of $\mathrm{Q}$ in the membrane, we replaced the region encoding the $\mathrm{Q} \mathrm{N}$-terminal cytoplasmic domain and TMD (codons 2-43) with the $\mathrm{N}$-terminal coding sequence from the Escherichia coli malF gene (codons 2-38) (Fig. 1B). MalF is an integral membrane protein that, like $\mathrm{Q}$, has a small N-terminal cytoplasmic domain followed by an in $\rightarrow$ out TMD. Importantly, if the Q TMD functions solely to orient the Q protein properly in the membrane, then the MalF TMD might substitute for this function. Conversely, if the Q N-terminal cytoplasmic region and/or TMD play additional roles in $\mathrm{Q}$ activity, then the malF ${ }^{T M D}-Q$ chimera should not be functional. Strikingly, we found that the $\operatorname{malF}^{T M D}-Q$ chimera supported sporulation to a substantial extent $\left(\sim 30 \%\right.$ of $Q^{+}$levels) (Fig. 1C). Furthermore, malF $F^{T M D}-Q$ cells displayed significant $\sigma^{\mathrm{G}}$ activity $\left(\sim 50 \%\right.$ of $Q^{+}$levels $)$ (Fig. 2B), and proper GFP-AH localization (although we did note that a small population of GFP-AH was mislocalized throughout the mother cell membranes) (Fig. 2D). These results are consistent with the idea that the Q $\mathrm{N}$ terminus and TMD are needed for the proper topology of $\mathrm{Q}$, but that the specific amino acid sequence of the region is largely dispensable.

Finally, we deleted the codons corresponding to His202-Pro216 in the context of the malF ${ }^{T M D}-Q$ chimeric gene. Cells harboring malF ${ }^{T M D}-Q^{\Delta 202-216}$, like $Q^{\Delta 202-216}$, were defective for spore formation (Fig. 1C), $\sigma^{\mathrm{G}}$ activation (Fig. 2B), and GFP-AH localization (Fig. 2D). We therefore conclude, in toto, that the extracellular domain of $Q$ is sufficient (when oriented properly relative to the membrane) for Q-mediated spore formation, $\sigma^{\mathrm{G}}$ activation, and $\mathrm{AH}$ localization, and that these functions rely in all cases on the conserved Q residues His202Pro216. Importantly, these results are consistent with a model in which the Q extracellular domain (which includes residues His202-Pro216) is sufficient to mediate assembly and function of the channel; in contrast, the specific residues of the $\mathrm{Q} N$ terminus and TMD appear to be dispensable in this regard.

A late phase of $\sigma^{F}$ activity is unmasked in mutant cells lacking $\sigma^{G}$ and requires $A A-A H$ and $Q$ residues His202-Pro216

In a parallel line of investigation, we discovered that the early-acting forespore $\sigma$ factor $\sigma^{\mathrm{F}}$ displays a late mode of activity in the absence of $\sigma^{\mathrm{G}}$, which ordinarily replaces $\sigma^{\mathrm{F}}$ at late times in the forespore (Li and Piggot 2001). To measure $\sigma^{\mathrm{F}}$ activity, we monitored the expression of a lacZ reporter gene fused to the $Q$ promoter $\left(\mathrm{P}_{\mathrm{Q}}\right)$, which is exclusively activated by $\sigma^{\mathrm{F}}$ (Londoño-Vallejo et al. 1997). As shown in Figure 3A, $\mathrm{P}_{\mathrm{Q}}-1 a c Z$ expression commenced $\sim 1.5-2 \mathrm{~h}$ after the onset of sporulation, consistent with previous reports (Londoño-Vallejo et al. 1997), and reached a maximal level of $\beta$-galactosidase expression at hour 2.5. In contrast, little $\beta$-galactosidase was detected when the gene for $\sigma^{\mathrm{F}}(\operatorname{sig} F)$ was deleted, confirming the dependence of $\mathrm{P}_{\mathrm{Q}}$-lac $Z$ expression on this $\sigma$ factor (Fig. 3A). Strikingly, we observed a notable change in the extent of $\sigma^{\mathrm{F}}$-directed $\mathrm{P}_{\mathrm{Q}}$-lac $Z$ expression in a strain deleted for the gene $(\operatorname{sig} G)$ encoding $\sigma^{\mathrm{G}}$. More specifically, $\sigma^{\mathrm{F}}$ activity at early times (through hour 2.5) was unaffected in $\operatorname{sig} G$ mutant cells; however, $\sigma^{\mathrm{F}}$ activity persisted at intermediate to late times of sporulation in mutant cells lacking $\sigma^{\mathrm{G}}$, reaching maximal $\beta$-galactosidase 

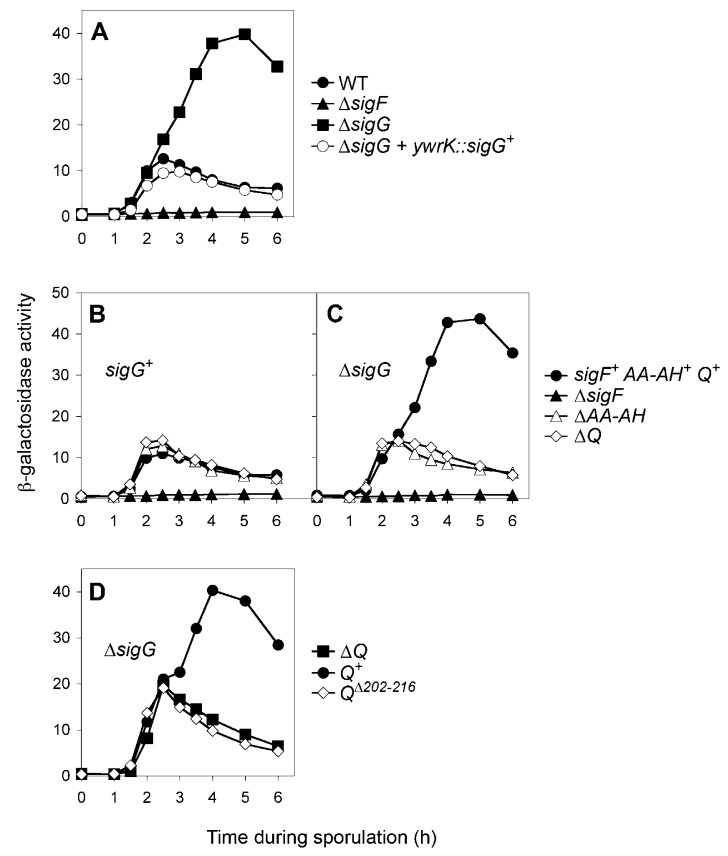

Figure 3. A late phase of $\sigma^{\mathrm{F}}$ activity is unmasked in the absence of $\sigma^{\mathrm{G}}$ and requires channel proteins. $(A) \sigma^{\mathrm{F}}$-dependent $\mathrm{P}_{\mathrm{Q}^{-}}-\mathrm{lac} Z$ expression during sporulation of wild-type cells $\left(\mathrm{WT}_{\text {; }}\right.$ closed circles), cells deleted for the gene encoding $\sigma^{\mathrm{F}}(\Delta \operatorname{sig} F$; closed triangles), deleted for the gene encoding $\sigma^{\mathrm{G}}$ ( $\Delta$ sigG; closed squares), or deleted for $\operatorname{sig} G$ and harboring a wild-type copy of the sigG gene inserted at the ywrK locus $\left(\Delta \operatorname{sig} G+y w r K:: s i g G^{+}\right.$; open circles) (strains AHB881, AHB938, AHB882, and AHB1305, respectively). In each of these strains and those described below, the $\mathrm{P}_{\mathrm{Q}}-1 a c Z$ reporter gene was inserted at the amyE locus. $(B, C)$ $\sigma^{\mathrm{F}}$-dependent $\beta$-galactosidase production in cells deleted for $\operatorname{sig} F$, $A A-A H$, or $Q$ in the presence $(B)$ or absence $(C)$ of the sig $G$ gene $\left(\operatorname{sig} G^{+}\right.$vs. $\left.\Delta \operatorname{sig} G\right)$. Cells expressing the $\mathrm{P}_{Q^{-}}$lac $Z$ reporter gene either harbored the wild-type $\operatorname{sig} F, A A-A H$ and $Q$ genes $\left(\operatorname{sig} F^{+}\right.$ $A A-A H^{+} Q^{+}$; closed circles) or were deleted for sigF ( $\Delta$ sigF; closed triangles), $A A-A H(\triangle A A-A H$; open triangles) or $Q(\Delta Q$; open diamonds) (sig $G^{+}$strains: AHB881, AHB938, AHB1134, and AHB939, respectively; sigG deletion strains: AHB882, AHB915, $\mathrm{AHB} 1017$, and AHB916, respectively). (D) $\sigma^{\mathrm{F}}$-dependent $\mathrm{P}_{\mathrm{Q}}-\mathrm{lacZ}$ activity during sporulation of strains lacking $\sigma^{\mathrm{G}}$ and producing mutant Q protein lacking residues His202-Pro216. Each strain harbored a deletion of the $\operatorname{sig} G$ gene. Additionally, the strains were deleted for $Q(\Delta Q$; closed squares) or were deleted for $Q$ and harbored at the sacA locus $Q^{+}$(closed circles) or the $Q^{\Delta 202-216}$ mutant (open diamonds) (strains AHB1453, AHB1463, and AHB1470, respectively).

levels (approximately two to four times that seen in wild type) at hours 4-5 (Fig. 3A). Reintroduction of a wild-type copy of the $\operatorname{sig} G$ gene at the nonessential ywrK locus complemented this late $\sigma^{\mathrm{F}}$ derepression phenotype, confirming that this effect is due specifically to the absence of $\sigma^{\mathrm{G}}$ (Fig. 3A). It appears, therefore, that $\sigma^{\mathrm{G}}$ (directly or indirectly) shuts down $\sigma^{\mathrm{F}}$ activity in the forespore, and that in the absence of $\sigma^{\mathrm{G}}$ a late phase of $\sigma^{\mathrm{F}}$ activity is unmasked, as also observed by P. Piggot (pers. comm.).

This discovery immediately raised the question of whether $\sigma^{\mathrm{F}}$ activity at late times is also dependent on the channel proteins (Q and $\mathrm{AA}-\mathrm{AH})$ that are needed for
$\sigma^{\mathrm{G}}$ activation. To test this idea, we introduced deletions of the $Q$ gene or the entire spoIIIA operon $(A A-A H)$ into the sig $G$ mutant strain harboring the $\sigma^{\mathrm{F}}$-dependent $\mathrm{P}_{\mathrm{Q}}$-lacZ reporter gene. Strikingly, we observed that the late $\sigma^{\mathrm{F}}$ activity unmasked by $\operatorname{sig} G$ deletion was almost completely abolished in the absence of $\mathrm{Q}$ or $\mathrm{AA}-\mathrm{AH}$ (Fig. 3C). We confirmed, however, that the $Q$ and $A A-A H$ deletions had no effect on the typical, early $\sigma^{\mathrm{F}}$ activity in an otherwise wild-type (i.e., $\operatorname{sig} G^{+}$) strain background (Fig. 3B). As a control, we confirmed that $\operatorname{sig} F$ was required for all $\mathrm{P}_{\mathrm{Q}}-1 a c Z$ activity regardless of the presence or absence of sigG (Figs. 3B,C). Finally, we tested whether late $\sigma^{\mathrm{F}}$ activity specifically required the block of conserved residues in the Q protein (His202-Pro216) that we identified as necessary for $\sigma^{\mathrm{G}}$ activation, presumably by mediating channel assembly. As shown in Figure 3D, cells harboring $Q^{\Delta 202-216}$ did not display late $\sigma^{\mathrm{F}}$-dependent $\beta$-galactosidase synthesis in the absence of $\sigma^{\mathrm{G}}$. We therefore conclude that at late times in sporulation, $\sigma^{\mathrm{F}}$-directed gene expression has the same or similar dependence on the channel proteins as does that for $\sigma^{\mathrm{G}}$.

$A A-A H$ and $Q$ residues His202-Pro216 are required for the late activity of a heterologous RNA polymerase in the forespore

The discovery that both $\sigma^{\mathrm{G}}$-directed and $\sigma^{\mathrm{F}}$-directed gene expression are dependent on $\mathrm{Q}$ and $\mathrm{AA}-\mathrm{AH}$ at late times indicates that $\mathrm{AA}-\mathrm{AH} \bullet \mathrm{Q}$ channel is not part of a dedicated signal transduction pathway for $\sigma^{\mathrm{G}}$. Instead, and as we herein propose, perhaps the channel has a broader function, such as a delivery system for small molecules needed generally for macromolecular synthesis in the forespore. If such a "feeding tube" model is correct, then gene expression directed by a heterologous RNA polymerase in the forespore also ought to be dependent on the channel.

To test this prediction, we engineered cells to produce phage T7 RNA polymerase (T7 RNAP) in the forespore. To do this, we placed the gene encoding T7 RNAP under the control of $P_{Q}$, which is activated by $\sigma^{\mathrm{F}}$ in the forespore, and integrated the resulting $\mathrm{P}_{Q^{-}}$T7 RNAP construct at the amyE locus. To monitor T7 RNAP-directed gene expression, we fused a T7 RNAP-recognized promoter $\left(\mathrm{P}_{T 7}\right)$ with optimized translational signals to a lac $Z$ reporter gene. The resulting $\mathrm{P}_{T 7}-l a c Z$ reporter was inserted at the $y w r K$ locus. As shown in Figure 4B, cells harboring both constructs $\left(a m y E:: \mathrm{P}_{Q^{-}} T 7 \quad R N A P\right.$ and $\left.y w r K:: \mathrm{P}_{T 7}-1 a c Z\right)$ switched on the synthesis of $\beta$-galactosidase at hour 2 of sporulation and did so in a manner that relied both on the presence of the $\mathrm{P}_{Q^{-}} T 7$ RNAP construct (data not shown) and on $\sigma^{\mathrm{F}}$ (Fig. 4B). We also found that cells harboring $\mathrm{P}_{\mathrm{Q}^{-}}$T7 RNAP and $\mathrm{P}_{T 7}-1 a c Z$ produced wildtype levels of spores (data not shown). Thus, the production of $\beta$-galactosidase by a heterologous RNA polymerase in the forespore did not interfere with the normal process of sporulation.

Next, we asked whether T7 RNAP-directed $\beta$-galactosidase synthesis became dependent on the channel proteins $Q$ 
A
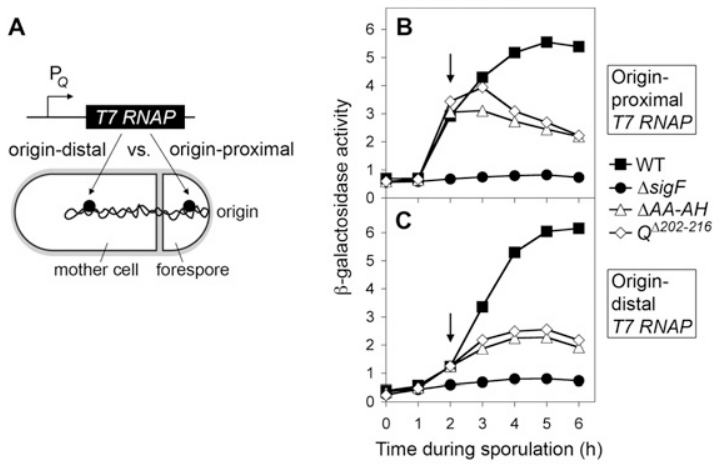

D

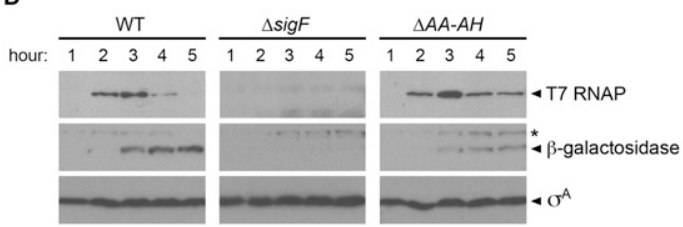

Figure 4. Late activity of a heterologous RNA polymerase requires the $\mathrm{AA}-\mathrm{AH}$ and $\mathrm{Q}$ channel proteins. $(A)$ Cartoon of the construct used to direct synthesis of T7 RNAP (T7 RNA polymerase) in the forespore during sporulation. The gene encoding T7 RNAP was placed under the control of the $\sigma^{\mathrm{F}}$-dependent $\mathrm{P}_{\mathrm{Q}}$ promoter and was integrated into the chromosome at either the origin-proximal amyE locus or at an origindistal location downstream from the $y \ln F$ gene. The proximity of the $\mathrm{P}_{\mathrm{Q}}-T 7$ RNAP construct to the origin of replication (which is anchored to the forespore pole of the sporangium) determines whether it will be present in the forespore immediately following asymmetric septation or following a delay. For simplicity, only the forespore chromosome is shown. $(B, C)$ T7 RNAPdirected $\mathrm{P}_{T 7}$-lac $Z$ expression during sporulation of wild-type cells (WT; black squares), cells deleted for sigF (open circles) or $A A-A H$ (open triangles), or cells engineered to express $Q^{\Delta 202-216}$ (open diamonds). In $B$, all strains harbor the $\mathrm{P}_{Q}-T 7$ RNAP construct integrated at an origin-proximal chromosome position (the $a m y E$ locus), whereas $C$ shows the results from corresponding strains with the $\mathrm{P}_{Q^{-}}$T7 RNAP construct inserted at an origindistal position (downstream from $y \ln F$ ). In all strains, the $\mathrm{P}_{T 7^{-}}$ lac $Z$ reporter was located at an origin-proximal position (the ywrK locus). Arrows highlight the difference in $\beta$-galactosidase levels at an early time of sporulation (hour 2) that results from switching the $\mathrm{P}_{Q^{-}}$T7 RNAP chromosome position. Origin proximal T7 RNAP strains: AHB1125 (WT), AHB1131 ( $\Delta$ sigF), AHB1132 $(\triangle A A-A H)$, and AHB1382 $\left(Q^{\Delta 202-216}\right)$. Origin distal T7 RNAP strains: AHB1449 (WT), AHB1474 ( $\Delta$ sigF), AHB1475 $(\triangle A A-A H)$, and AHB1545 $\left(Q^{\Delta 202-216}\right)$. (D) Immunoblot analysis of whole-cell extracts from sporulating wild-type cells (WT; left panel) or cells deleted for sigF (center panel), or $A A-A H$ (right panel), using antibodies to T7 RNAP, $\beta$-galactosidase, or, as a loading control, $\sigma^{\mathrm{A}}$. An asterisk marks a protein that displays cross-reactivity with the anti- $\beta$-galactosidase antibody. Strains were identical to those used in $C$, with $\mathrm{P}_{Q^{-}}$T7 RNAP integrated at an origin-distal chromosome position: AHB1449 (WT), $\mathrm{AHB} 1474(\Delta \operatorname{sig} F)$, and $\mathrm{AHB1475}(\Delta A A-A H)$.

and $\mathrm{AA}-\mathrm{AH}$ at late times in sporulation. Figure $4 \mathrm{~B}$ shows that the loss-of-function $Q^{\Delta 202-216}$ mutation or an $A A-A H$ deletion mutation permitted wild-type levels of T7 RNAP activity at early times in sporulation (through hours 2-3), but strikingly, impaired additional $\beta$-galactosidase production after hour 3 . These results suggest that T7 RNAP-directed gene expression occurred in two phases: an early phase that was independent of AA-AH and Q residues His202-Pro216, and a late phase that required these channel proteins. Chromosome position of $P_{Q}-T 7$ RNAP influences the
proportion of channel-dependent T7 RNAP activity

We interpret our results to indicate that T7 RNAP displays an early, channel-independent phase of activity in the forespore, followed by a late phase that is dependent on the $\mathrm{AA}-\mathrm{AH} \bullet \mathrm{Q}$ channel. If so, then it should be possible to increase the proportion of channel-dependent activity by delaying the onset of T7 RNAP synthesis. To do this, we took advantage of the fact that immediately following asymmetric septation, only the origin-proximal $\sim 30 \%$ of the forespore chromosome is present in the forespore compartment (Fig. 4A; Wu and Errington 1998). The remainder of the chromosome is then translocated across the septum into the forespore in a process that has been reported to take 10-20 min (Pogliano et al. 1999; Khvorova et al. 2000; Burton et al. 2007). As a consequence of this transient genetic asymmetry, $\sigma^{\mathrm{F}}$ target genes present near the origin are activated earlier than those present near the terminus (Khvorova et al. 2000; Burton et al. 2007).

In our original engineered strain, the $\mathrm{P}_{Q^{-}}-77 R N A P$ construct was inserted at the amyE locus, which is origin-proximal (located at chromosome map position $28^{\circ}$ relative to the origin $\left.\left[0^{\circ}\right]\right)$ and as such is immediately accessible to $\sigma^{\mathrm{F}}$ in the forespore. We therefore reconstructed the strain, moving the $\mathrm{P}_{\mathrm{Q}}-$ T7 RNAP construct to an origin-distal location (downstream from the $y \ln F$ locus at chromosome map position $140^{\circ}$ ) that should not be accessible to $\sigma^{\mathrm{F}}$ until chromosome translocation has occurred (Fig. 4A). Whereas the origin-proximal $\mathrm{P}_{\mathrm{Q}^{-}}$ T7 RNAP strain reached $\sim 50 \%$ maximal $\beta$-galactosidase production by hour 2 (Fig. 4B), the reconstructed strain with the origin-distal construct did not accumulate equivalent levels of $\beta$-galactosidase until hour 3 (Fig. 4C). Thus, T7 RNAP-directed $\beta$-galactosidase synthesis was delayed when the $\mathrm{P}_{Q^{-}}$T7 RNAP construct was moved to the origin-distal location, perhaps even more so than might have been expected from earlier work (Pogliano et al. 1999; Khvorova et al. 2000; Burton et al. 2007).

We then measured the dependence of T7 RNAP activity on the $\mathrm{Q}$ and $\mathrm{AA}-\mathrm{AH}$ channel proteins in the origindistal $\mathrm{P}_{Q^{-}}$T7 RNAP strain background. As shown in Figure 4C, T7 RNAP activity was significantly reduced by deletion of $A A-A H$ or introduction of the loss-offunction $Q^{\Delta 202-216}$ mutation. Moreover, as we predicted, the effect of these mutations during late sporulation was more marked in this origin-distal $\mathrm{P}_{Q^{-}}$T7 RNAP strain. Whereas the (original) origin-proximal $\mathrm{P}_{\mathrm{Q}^{-}}$T7 RNAP strain still displayed up to $\sim 50 \%$ maximal wild-type $\mathrm{P}_{T 7}-1 a c Z$ activity in the absence of $\mathrm{AA}-\mathrm{AH}$ or $\mathrm{Q}$ function (due to the strong early, channel-independent activity) (Fig. 4B), the reconstructed origin-distal $\mathrm{P}_{\mathrm{Q}}-T 7$ RNAP strain, which had a reduced early phase of activity, only 
reached $\sim 30 \%$ maximal wild-type T7 RNAP activity levels (Fig. 4C). Because the origin-distal $\mathrm{P}_{\mathrm{Q}}-T 7$ RNAP strain better emphasized the late requirement for the channel proteins Q and AA-AH in T7 RNAP activity, all experiments presented henceforth were performed in this strain background.

As a control, we confirmed that levels of the T7 RNAP protein itself were not affected by the absence of the AA$\mathrm{AH} \cdot \mathrm{Q}$ channel. As shown in Figure $4 \mathrm{D}$, wild-type and $A A-A H$ mutant cells (the same as shown in Fig. 4C) produced the heterologous RNA polymerase with similar timing and to similar levels during sporulation (cf. left and right panels). In contrast, $\beta$-galactosidase protein levels, as expected, were significantly reduced in the $A A-A H$ deletion strain at late times. Neither T7 RNAP nor $\beta$-galactosidase protein were detectable in extracts from cells deleted for $\operatorname{sig} F$ (Fig. 4D, middle panel). These findings indicate that reduced T7 RNAP-dependent $\beta$-galactosidase synthesis in the absence of the channel is not due to differences in T7 RNAP protein levels. Instead, and in toto, our results indicate that the $\mathrm{AA}-\mathrm{AH} \cdot \mathrm{Q}$ channel is needed to maintain the transcriptional and/ or translational activity of the forespore late in sporulation or at least that governed by a heterologous RNA polymerase.

\section{Use of T7 RNAP unmasks an inhibitory function of $Q$ in the forespore}

During the course of these experiments we unexpectedly observed that certain alterations to the $\mathrm{N}$-terminal region of Q caused a large increase in T7 RNAP-directed gene expression. Specifically, replacement of wild-type $\mathrm{Q}$ with the MalF ${ }^{\mathrm{TMD}}-\mathrm{Q}$ chimera caused expression of the $\mathrm{P}_{T 7^{-}}$ lac $Z$ reporter to increase fivefold to 10 -fold (Fig. 5A). Also, replacement of the highly conserved Tyr28 (Fig. 1B; Supplemental Fig. S1), which is predicted to be embedded in the TMD, with an alanine (yielding the $\mathrm{Q}^{\mathrm{Y} 28 \mathrm{~A}}$ variant) similarly enhanced T7 RNAP-directed gene expression severalfold (Fig. 5A). In comparison, we did not detect a comparable effect of the Tyr28 substitution on $\sigma^{\mathrm{G}}$-directed gene expression or a measureable effect on sporulation (data not shown). We suspect that T7 RNAP is particularly sensitive to a normal but subtle role of Tyr28 in sporulation that we have not yet uncovered.

The results with MalF ${ }^{\mathrm{TMD}}-\mathrm{Q}$ and the Tyr28 substitution indicate that $\mathrm{Q}$ has opposing effects on T7 RNAPdirected gene expression: inhibition of T7 RNAP activity, which is mediated by the N-terminal region, and stimulation of polymerase activity, which involves the C-terminal extracellular region. If this interpretation is correct, then it should be possible to separate the two regions of $\mathrm{Q}$ as discrete functional molecules. Accordingly, we constructed a strain that coexpressed two $Q$ variants, one encoding only the first 53 residues of $\mathrm{Q}$ $\left(Q^{\Delta C 230}\right.$, integrated at $\left.\operatorname{sac} A\right)$ and the other encoding only the extracellular domain of $\mathrm{Q}$ fused to the $\mathrm{N}$-terminal TMD of MalF (the alF $^{T M D}-Q$ chimera, integrated at the nonessential lacA locus). Importantly, the $\mathrm{Q}^{\Delta \mathrm{C} 230}$ and MalF ${ }^{\mathrm{TMD}}$-Q proteins share only 10 amino acids in com-

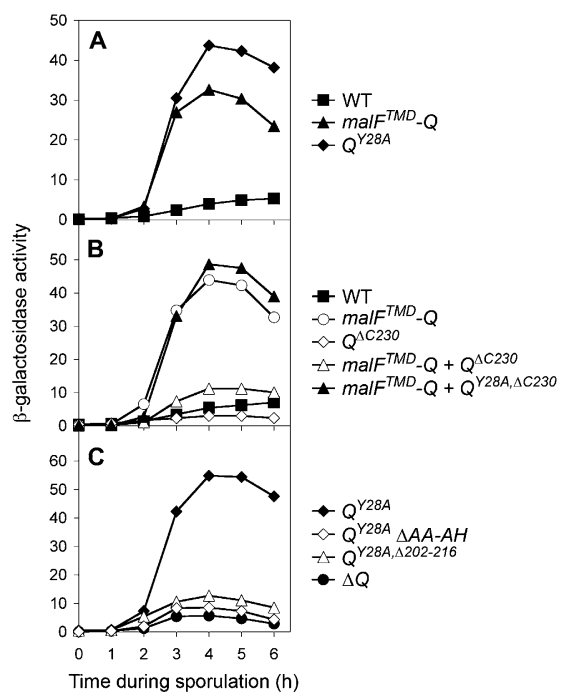

Figure 5. $\mathrm{Q}$ is a bifunctional protein. $(A)$ Forespore-specific $\mathrm{T} 7$ RNAP-directed $\mathrm{P}_{T 7}-1 a c Z$ activation during sporulation of strains expressing $Q^{+}$(solid squares), malF ${ }^{T M D}-Q$ (solid triangles), or $Q^{Y 28 A}$ (solid diamonds) (strains AHB1542, AHB1547, and AHB1543, respectively). In each of these strains and those described below, the construct expressing T7 RNAP $\left(\mathrm{P}_{Q^{-}}-\mathrm{T} 7\right.$ $R N A P \mid$ was inserted at the origin-distal $y \ln F$ locus, whereas the $\mathrm{P}_{T 7}-1 a c Z$ reporter gene was integrated at the origin-proximal ywrK gene. (B) T7 RNAP-directed $\beta$-galactosidase production in strains harboring the $\mathrm{P}_{T 7}-1 a c Z$ reporter and coexpressing the alleles malF $F^{T M D}-Q$ and $Q^{\Delta C 230}$ (open triangles; strain AHB1571) or malF $F^{T M D}-Q$ and $Q^{Y 28 A, \Delta C 230}$ (closed triangles; strain AHB1579). Data for control strains expressing wild-type $Q\left(Q^{+}\right.$; closed squares), $m a l F^{T M D}-Q$ (open circles) or $Q^{\Delta C 230}$ (open diamonds) alone are also shown (strains AHB1542, AHB1567, and AHB1544, respectively). (C) T7 RNAP-dependent $\mathrm{P}_{T 7}-$ lacZ reporter gene activity was measured during sporulation of strains expressing $Q^{Y 28 A}$ (closed diamonds), $Q^{Y 28 A}$ and deleted for $A A-A H$ (open diamonds), $Q^{Y 28 A, \Delta 202-216}$ (open triangles), or deleted for $Q$ altogether ( $\Delta Q$; closed circles) (strains AHB1543, AHB1562, AHB1546, and AHB1476, respectively).

mon (residues 44-53 of full-length Q). If the Q N-terminal and extracellular C-terminal domains indeed function separately to influence T7 RNAP in the forespore, then expression of these two domains on individual molecules ought to restore the wild-type profile of T7 RNAPdirected gene activation. Indeed, we observed that the profile of T7 RNAP-dependent $\beta$-galactosidase production in cells harboring both constructs $\left(Q^{\Delta C 230}\right.$ and malF $\left.{ }^{T M D}-\mathrm{Q}\right)$ approximately phenocopied that observed in wild-type cells (Fig. 5B). This result indicates that, at most, only a subtle difference in T7 RNAP activity is apparent when the $\mathrm{N}$-terminal and extracellular regions of $\mathrm{Q}$ are provided on a separate molecules. As a control, we found that switching the Tyr28 codon to an alanine codon in the $Q^{\Delta C 230}$ construct destroyed this cooperation (Fig. 5B). Therefore, we conclude that Q protein is bifunctional, and that the inhibitory action of the Q N terminus on T7 RNAP is mediated by a separate region of $\mathrm{Q}$ than that involved in channel formation; moreover, these two functions can be provided on separate molecules. 
Hyperactive T7 RNAP remains dependent on the $A A-A H \cdot Q$ channel at late times in the forespore

If our hypothesis that macromolecular synthesis in the forespore becomes dependent on the channel is correct, then the enhanced level of T7 RNAP activity seen in the $Q^{Y 28 A}$ mutant also ought to be dependent on the AA$\mathrm{AH} \cdot \mathrm{Q}$ channel. As a test of this expectation, we introduced a deletion of $A A-A H$ into cells harboring $Q^{Y 28 A}$; strikingly, T7 RNAP-dependent $\beta$-galactosidase production was reduced approximately fivefold at late times in the double mutant (Fig. 5C). Likewise, a strain harboring a $\mathrm{Q}$ variant simultaneously mutated for Tyr28 and deleted for residues His202-Pro216 $\left(\mathrm{Q}^{\mathrm{Y} 28 \mathrm{~A}, \Delta 202-216}\right)$ was reduced severalfold for T7 RNAP activity as compared with the $Q^{Y 28 A}$ parent strain (Fig. 5C). Similar results were also seen simply by deleting the entire $Q$ gene (Fig. 5C). That is, the level of T7 RNAP activity in a Q-null mutant was severalfold lower than in the $Q^{Y 28 A}$ mutant. Therefore, we conclude that channel activity, which requires AA-AH and Q residues His202-Pro216, is critical for gene activation by T7 RNAP at late times in the forespore, even under conditions when the separate inhibitory function of $\mathrm{Q}$ is abrogated.

\section{Discussion}

\section{A feeding tube model for activation of $\sigma^{G}$}

The forespore transcription factor $\sigma^{\mathrm{G}}$ is activated by an intercellular pathway that is dependent on the protein products (AA-AH) of the eight-cistron spoIIIA operon, which is transcribed in the mother cell under the direction of $\sigma^{\mathrm{E}}$. We and others have proposed that the AA$\mathrm{AH}$ proteins, together with the forespore protein $\mathrm{Q}$, constitute a channel (referred to here as the AA-AH・Q channel) that interconnects the two compartments of the developing sporangium (Camp and Losick 2008; Meisner et al. 2008). A traditional view of the regulation of $\sigma^{\mathrm{G}}$ holds that its activation in the forespore is governed by a specific activator of $\sigma^{\mathrm{G}}$ or an antagonist (an anti-anti- $\sigma^{\mathrm{G}}$ factor) of an antagonist of $\sigma^{\mathrm{G}}$ (an anti- $\sigma^{\mathrm{G}}$ factor). Indeed, Meisner et al. (2008) have suggested that the channel is responsible for the transport of a protein that specifically triggers $\sigma^{G}$ activation in the forespore. If so, the identity of the protein remains unknown, and recent evidence has argued against the involvement of two proteins (CsfB and SpoIIAB) that were known to acts as anti- $\sigma^{\mathrm{G}}$ factors (Evans et al. 2003; Serrano et al. 2004; Chary et al. 2005; Camp and Losick 2008).

Here we propose a new model for the regulation of $\sigma^{\mathrm{G}}$ that does not invoke the existence of a specific regulator of the forespore $\sigma$ factor. Instead, evidence indicates that the AA-AH and Q proteins are needed not only for $\sigma^{\mathrm{G}}$ activity but also for the activity of $\sigma^{\mathrm{F}}$ at late times during sporulation and, strikingly, even for the activity of a heterologous enzyme, the phage T7 RNA polymerase (T7 RNAP). Hence, the AA-AH・Q channel appears to be generally required for macromolecular synthesis in the forespore. In light of these considerations, we suggest that the channel is a conduit through which the mother cell feeds, or nurtures the forespore, providing one or more small molecules generally required for RNA or protein synthesis or both.

Why would the forespore come to depend on the mother cell for macromolecular synthesis? We speculate that at an intermediate stage of sporulation, when engulfment is nearing completion, the autonomous transcriptional and/or translational capacity of the forespore diminishes as a passive consequence of its increasing sequestration within the cytoplasm of the mother cell. Alternatively, an active mechanism may be responsible for shutting down nucleotide and amino acid synthesis and/or energy production in the forespore, which is destined to become metabolically inert, at the time of engulfment. For example, Marquis et al. (2008) have shown recently that vegetative gene expression directed by $\sigma^{\mathrm{A}}$ is down-regulated in the forespore due to "stripping" of DNA-binding proteins off the forespore chromosome as it is pumped across the septum.

If our feeding tube model is correct, then what is the nature of the compounds that are transported into the forespore by the AA-AH・Q channel? Perhaps the channel transports a variety of small molecules, such as nucleotides and amino acids, which are required for macromolecular synthesis. In this case, it is possible that the channel provides an aqueous pore through which these small molecules move by passive transport, analogous to eukaryotic gap junctions (Kumar and Gilula 1996). Alternatively, and conceivably, the channel is dedicated to the transport of a single small molecule, such as, for example, ATP. A second related question is whether the AA-AH $\bullet \mathrm{Q}$ channel is gated, and if so, how this gating is regulated. Recently published biochemical evidence from Meisner et al. (2008) suggests that the AA-AH•Q channel is open on the forespore side but gated on the mother cell side. One intriguing possibility is that the channel is opened as engulfment nears completion, as it is known that $\sigma^{\mathrm{G}}$ is activated at or near the time that the forespore is pinched off as a free protoplast in the mother cell. Because the space between the inner and outer forespore membranes eventually becomes filled with a cortex of cell wall material, we presume that the channel must eventually close or becomes disabled as the cortex thickens. Consistent with this idea, Meisner et al. (2008) have shown that the channel, as detected by accessibility of the $\mathrm{AH}$ extracellular domain from the forespore cytoplasm, disappears soon after the completion of forespore engulfment.

Finally, we come back to the implications of the feeding tube model for $\sigma^{\mathrm{G}}$ regulation in the forespore. While this model provides a satisfying explanation for $\sigma^{G}$ inactivity in the absence of the channel at late times of sporulation, it remains unclear why $\sigma^{\mathrm{G}}$ is also inactive at early times during sporulation in $A A-A H$ or $Q$ mutant cells. As discussed above, we propose that the forespore harbors the resources necessary for transcription and translation at early times, and that it is only at intermediate to late times of sporulation that the transport of metabolites through the channel becomes critical for gene activation. Indeed, we observed that both $\sigma^{\mathrm{F}}$ and 
T7 RNAP display early activity (between hours 2 and 3 of sporulation) that is unaffected by the absence of AA-AH or Q, but that in both cases later activity (after hour 3 ) is strongly dependent on the channel proteins. In contrast, no corresponding early, channel-independent phase of $\sigma^{\mathrm{G}}$ activity is observed in $A A-A H$ or $Q$ mutant cells (Camp and Losick 2008). We speculate that the absence of substantial $\sigma^{\mathrm{G}}$ activity at early times is due to several factors, including weak $\sigma^{\mathrm{F}}$-dependent transcription of the gene $(\operatorname{sig} G)$ that encodes $\sigma^{\mathrm{G}}$ (A.H. Camp and R. Losick, in prep.), post-transcriptional inhibition of $\sigma^{\mathrm{G}}$ by CsfB (Chary et al. 2007; Karmazyn-Campelli et al. 2008), and competition of $\sigma^{\mathrm{G}}$ with $\sigma^{\mathrm{F}}$ for binding to core RNA polymerase (but see also Chary et al. 2006).

\section{A conserved region of $Q$ mediates $\sigma^{G}$ activation and AH localization}

An additional contribution of the present investigation is the identification of a conserved block of residues in the Q extracellular domain (His202-Pro216) that mediates $\sigma^{\mathrm{G}}$ activation and AH localization. The simplest interpretation of our results is that the His202-Pro216 region of $\mathrm{Q}$ contacts $\mathrm{AH}$, and therefore is directly responsible for bridging the channel between the mother cell and the forespore. Strictly speaking, however, we cannot exclude the possibility that the His202-Pro216 region is needed for proper folding of the $\mathrm{Q}$ extracellular domain and is not itself in direct contact with $\mathrm{AH}$.

A second conspicuous feature of $\mathrm{Q}$ is its transmembrane domain (TMD) located near the $\mathrm{N}$ terminus of the protein, which contains a highly conserved tyrosine at position 28 (Tyr28). Remarkably, however, the $\mathrm{N}$-terminal region of $\mathrm{Q}$ is largely dispensable, as its replacement with a heterologous, single-pass transmembrane segment from the MalF protein of $E$. coli caused only a modest impairment in $\sigma^{\mathrm{G}}$ activation and spore formation. Evidently, proper assembly of the channel merely requires that the conserved extracellular domain of $\mathrm{Q}$ is anchored to the forespore membrane, but the nature of how it is anchored is not critical for channel function.

\section{$Q$ is a bifunctional protein}

Complicating our investigation into the role of $\mathrm{Q}$ in creating a channel was the unexpected discovery of a second, cryptic function of Q. Although the TMD of Q could be replaced with that of $E$. coli MalF with only modest effect on sporulation, $\sigma^{\mathrm{G}}$ activation, and $\mathrm{AH}$ localization, alterations to the $\mathrm{N}$-terminal region of $\mathrm{Q}$ had a strong stimulatory effect on T7 RNAP activity. Specifically, T7 RNAP activity was increased fivefold to 10-fold in cells harboring $\mathrm{MalF}^{\mathrm{TMD}}-\mathrm{Q}$ or in cells harboring a substitution mutant of $\mathrm{Q}$ in which the highly conserved Tyr28 was replaced with alanine $\left(\mathrm{Q}^{\mathrm{Y} 28 \mathrm{~A}}\right)$. Importantly, even under conditions in which T7 RNAP activity was enhanced by alteration to the $\mathrm{N}$-terminal region, $\mathrm{T} 7$ RNAP-directed gene expression remained strongly dependent on the AA-AH・Q channel. That the $\mathrm{N}$-terminal region represents an independent functional domain of $\mathrm{Q}$ was compellingly demonstrated by the fact that the two Q functions could be provided on separate molecules. That is, the hyperactivity of T7 RNAP seen with $\mathrm{MalF}^{\mathrm{TMD}}-\mathrm{Q}$ was complemented with a separate, truncated $\mathrm{Q}$ protein solely representing the N-terminal region.

Our interpretation of these puzzling findings is that the $\mathrm{N}$-terminal region of $\mathrm{Q}$ mediates a second and independent function for which T7 RNAP is particularly sensitive. We suspect that the second function also somehow contributes to normal sporulation in that Tyr28 residue is highly conserved among Bacilli. Yet so far we have not detected a conspicuous phenotype that we can attribute to the Tyr28 $\rightarrow$ Ala substitution. A challenge for the future will be to elucidate the molecular basis for the effect on T7 RNAP activity and the role, if any, that Tyr 28 plays in sporulation. Although the nature of how Tyr28 influences T7 RNAP activity remains mysterious, our results clearly indicate that it represents a second independent function of $Q$ that is separate from the role of $\mathrm{Q}$ in creating what we have proposed is a feeding tube that links the forespore to the mother cell.

\section{Conclusions}

Our central finding is that dependence on the AA-AH・Q channel is not limited to the activity of $\sigma^{\mathrm{G}}$. Rather, at intermediates stages of sporulation, $\sigma^{\mathrm{F}}$-directed gene expression, as well as gene expression directed by a heterologous RNA polymerase, T7 RNAP, are also dependent on the channel proteins. The simplest interpretation of these observations is that the channel does not introduce a specific regulator of $\sigma^{\mathrm{G}}$ into the forespore. To the contrary, we argue that the channel is a feeding tube that provides one or more molecules, likely a small molecule, such as a nucleotide (e.g., ATP) and/or amino acid, that is generally needed for macromolecular synthesis in the forespore as it is being enveloped by the mother cell. If so, then the $\mathrm{AA}-\mathrm{AH} \cdot \mathrm{Q}$ channel would be the equivalent of a eukaryotic gap junction, bridging the cytoplasm of the mother cell and forespore to allow the diffusion of small molecules between the two compartments.

\section{Materials and methods}

\section{General methods}

Bacterial strains were propagated in Luria-Bertani medium, with antibiotics included, when appropriate, as follows: chloramphenicol $(5 \mu \mathrm{g} / \mathrm{mL})$, erythromycin plus lincomycin $(1 \mu \mathrm{g} / \mathrm{mL}$ and 25 $\mu \mathrm{g} / \mathrm{mL}$, respectively), spectinomycin $(100 \mu \mathrm{g} / \mathrm{mL})$, kanamycin $(5$ $\mu \mathrm{g} / \mathrm{mL})$, phleomycin $(0.4 \mu \mathrm{g} / \mathrm{mL})$, and ampicillin $(100 \mu \mathrm{g} / \mathrm{mL})$. To quantify spore formation, cells were induced to sporulate by nutrient exhaustion in Difco sporulation medium (DSM) (Schaeffer et al. 1965; Nicholson and Setlow 1990). After 24-h growth in DSM at $37^{\circ} \mathrm{C}$, the number of colony-forming units that survived heat treatment $\left(20 \mathrm{~min}\right.$ at $\left.80^{\circ} \mathrm{C}\right)$ was calculated. For all other experiments (including measurement of $l a c Z$ reporter gene activity, localization of GFP fusion proteins, and immunoblot analysis), sporulation was induced by the resuspension method (Sterlini and Mandelstam 1969; Nicholson and Setlow 1990). 
Cells were collected at intervals and either processed immediately or stored at $-80^{\circ} \mathrm{C}$ for later processing.

\section{Strain and plasmid construction}

All strains were derived from the prototrophic laboratory strain PY79 (Youngman et al. 1984). Details of strain and plasmid sources and construction are given in the Supplemental Material. Additionally, see Supplemental Table S1 for the full genotypes of strains, Supplemental Table S2 for a description of plasmids, and Supplemental Table S3 for a list of primers used in this study.

\section{Kinetic $\beta$-galactosidase assay}

To measure $\beta$-galactosidase activity, we developed a kinetic assay based on a previously described method (Nicholson and Setlow 1990). Briefly, cell pellets (corresponding to $1 \mathrm{~mL}$ of the original sporulating culture) were resuspended in $0.5 \mathrm{~mL}$ Z-buffer $160 \mathrm{mM} \mathrm{Na}_{2} \mathrm{HPO}_{4}, 40 \mathrm{mM} \mathrm{NaH}_{2} \mathrm{PO}_{4}, 10 \mathrm{mM} \mathrm{KCl}, 1 \mathrm{mM} \mathrm{MgSO}$ ， $50 \mathrm{mM} \beta$-mercaptoethanol at $\mathrm{pH}$ 7.0). Fifty microliters of these cells were added to individual wells of a clear 96-well plate containing $50 \mu \mathrm{L}$ of $0.4 \mathrm{mg} / \mathrm{mL}$ lysozyme in Z-buffer. Cell lysis was allowed to proceed for $20-30 \mathrm{~min}$ at $37^{\circ} \mathrm{C}$. Twenty microliters of $4 \mathrm{mg} / \mathrm{mL}$ 2-Nitrophenyl $\beta$-D-galactopyranoside (ONPG; Sigma-Aldrich) in Z-buffer were then added to each well and mixed thoroughly. Absorbance at $420 \mathrm{~nm}$ for each reaction was read once per minute for $1 \mathrm{~h}$ at $37^{\circ} \mathrm{C}$ in a Synergy 2 plate reader (BioTek). $\beta$-Galactosidase activity (in arbitrary units [AU]) is reported as the rate of ONPG conversion (i.e., $\mathrm{V}_{\max }$, with units of $\mathrm{mOD}_{420}$ per minute) divided by the $\mathrm{OD}_{600}$ of the sample at the time of collection. Standard curve analysis revealed that 1 $\mathrm{AU} \sim 4$ Miller units.

\section{Fluorescence microscopy}

Cells were prepared for fluorescence microscopy as follows: At hour 3 of sporulation, cells were harvested and resuspended in $1 \times$ PBS containing $1 \mu \mathrm{g} / \mathrm{mL}$ membrane stain FM 4-64 (Invitrogen). Cells were spotted onto a thin $1 \%$ agarose pad prepared on a glass slide and immobilized with a poly-L-lysine-treated coverslip. Fluorescence microscopy was performed with an Olympus BX61 microscope fitted with an Olympus UPlanF1 $100 \times$ phase-contrast objective. GFP fluorescence was visualized using filter set U-M41001 (excitation filter 455-495 nm, dichroic mirror $505 \mathrm{~nm}$, emission filter 510-555 nm), while FM 4-64 fluorescence was visualized using filter set U-MWG2 (excitation filter $510-550 \mathrm{~nm}$, dichroic mirror $570 \mathrm{~nm}$, barrier filter $>590$ $\mathrm{nm})$. Images were captured with an RTE/CCD-1300-Y/HS camera (Roper Scientific) using the Simple PCI imaging software version 6.0 (Hamamatsu Corporation). Exposure times were typically 500-1000 msec for both GFP and FM 4-64. Images were adjusted for brightness and contrast using Adobe Photoshop CS3 software.

\section{Immunoblot analysis}

Cell pellets (corresponding to $1 \mathrm{~mL}$ of the original sporulating culture) were resuspended in $75 \mu \mathrm{L}$ of lysis buffer (50 mM Tris at $\mathrm{pH} 7.5,50 \mathrm{mM}$ EDTA, $100 \mathrm{mM} \mathrm{NaCl}, 1 \mathrm{mg} / \mathrm{mL}$ lysozyme) and incubated for $10 \mathrm{~min}$ at $37^{\circ} \mathrm{C}$, followed by addition of $75 \mu \mathrm{L} 2 \times$ sodium dodecyl sulfate (SDS) sample buffer (100 mM Tris at $\mathrm{pH}$ $6.8,4 \%$ SDS, $0.2 \%$ bromophenol blue, $20 \%$ glycerol) containing $200 \mathrm{mM}$ dithiothreitol. Samples were heated for $5 \mathrm{~min}$ to $80^{\circ} \mathrm{C}$, and equal volumes $(15 \mu \mathrm{L})$ were separated by SDS-polyacrylamide gel electrophoresis and transferred to an Immobilon-P membrane (Millipore). Immunoblot analysis was performed with monoclonal anti-T7 RNAP antibodies (Novagen; diluted 1:5000), polyclonal anti- $\beta$-galactosidase antibodies (AbCam; diluted 1:5000), or polyclonal anti- $\sigma^{\mathrm{A}}$ antibodies (labratory stock; diluted $1: 40,000)$.

\section{Acknowledgments}

We thank S.-L. Ng for the construction of plasmids pAH124 and pAH136. We also thank A. Grossman and members of Losick laboratory for helpful discussions. This work was supported by a Helen Hay Whitney Foundation post-doctoral fellowship to A.H.C. and National Institute of Health grant GM18568 to R.L.

\section{References}

Blaylock, B., Jiang, X., Rubio, A., Moran Jr., C.P., and Pogliano, K. 2004. Zipper-like interaction between proteins in adjacent daughter cells mediates protein localization. Genes \& Dev. 18: 2916-2928.

Burton, B.M., Marquis, K.A., Sullivan, N.L., Rapoport, T.A., and Rudner, D.Z. 2007. The ATPase SpoIIIE transports DNA across fused septal membranes during sporulation in Bacillus subtilis. Cell 131: 1301-1312.

Camp, A.H. and Losick, R. 2008. A novel pathway of intercellular signalling in Bacillus subtilis involves a protein with similarity to a component of type III secretion channels. Mol. Microbiol. 69: 402-417.

Chary, V.K., Meloni, M., Hilbert, D.W., and Piggot, P.J. 2005. Control of the expression and compartmentalization of $\sigma^{\mathrm{G}}$ activity during sporulation of Bacillus subtilis by regulators of $\sigma^{\mathrm{F}}$ and $\sigma^{\mathrm{E}}$. J. Bacteriol. 187: 6832-6840.

Chary, V.K., Xenopoulos, P., and Piggot, P.J. 2006. Blocking chromosome translocation during sporulation of Bacillus subtilis can result in prespore-specific activation of $\sigma^{\mathrm{G}}$ that is independent of $\sigma^{\mathrm{E}}$ and of engulfment. J. Bacteriol. 188: 7267-7273.

Chary, V.K., Xenopoulos, P., and Piggot, P.J. 2007. Expression of the $\sigma^{\mathrm{F}}$-directed $\operatorname{csf} B$ locus prevents premature appearance of $\sigma^{\mathrm{G}}$ activity during sporulation of Bacillus subtilis. J. Bacteriol. 189: $8754-8757$.

Christie, P.J., Atmakuri, K., Krishnamoorthy, V., Jakubowski, S., and Cascales, E. 2005. Biogenesis, architecture, and function of bacterial type IV secretion systems. Annu. Rev. Microbiol. 59: 451-485.

Doan, T., Marquis, K.A., and Rudner, D.Z. 2005. Subcellular localization of a sporulation membrane protein is achieved through a network of interactions along and across the septum. Mol. Microbiol. 55: 1767-1781.

Evans, L., Clarkson, J., Yudkin, M.D., Errington, J., and Feucht, A. 2003. Analysis of the interaction between the transcription factor $\sigma^{\mathrm{G}}$ and the anti- $\sigma$ factor SpoIIAB of Bacillus subtilis. J. Bacteriol. 185: 4615-4619.

Firczuk, M., Mucha, A., and Bochtler, M. 2005. Crystal structures of active LytM. J. Mol. Biol. 354: 578-590.

Galan, J.E. and Wolf-Watz, H. 2006. Protein delivery into eukaryotic cells by type III secretion machines. Nature 444: 567-573.

Gallagher, K.L. and Benfey, P.N. 2005. Not just another hole in the wall: Understanding intercellular protein trafficking. Genes \& Dev. 19: 189-195.

Guillot, C. and Moran Jr., C.P. 2007. Essential internal promoter in the spoIIIA locus of Bacillus subtilis. J. Bacteriol. 189: 7181-7189.

Gustin, J.K., Kessler, E., and Ohman, D.E. 1996. A substitution at His-120 in the LasA protease of Pseudomonas aeruginosa blocks enzymatic activity without affecting propeptide 
processing or extracellular secretion. J. Bacteriol. 178: 66086617.

Hilbert, D.W. and Piggot, P.J. 2004. Compartmentalization of gene expression during Bacillus subtilis spore formation. Microbiol. Mol. Biol. Rev. 68: 234-262.

Illing, N. and Errington, J. 1991. The spoIIIA operon of Bacillus subtilis defines a new temporal class of mother-cell-specific sporulation genes under the control of the $\sigma^{\mathrm{E}}$ form of RNA polymerase. Mol. Microbiol. 5: 1927-1940.

Karmazyn-Campelli, C., Rhayat, L., Carballido-Lopez, R., Duperrier, S., Frandsen, N., and Stragier, P. 2008. How the early sporulation $\sigma$ factor $\sigma^{\mathrm{F}}$ delays the switch to late development in Bacillus subtilis. Mol. Microbiol. 67: 1169-1180.

Kellner, E.M., Decatur, A., and Moran Jr., C.P. 1996. Two-stage regulation of an anti- $\sigma$ factor determines developmental fate during bacterial endospore formation. Mol. Microbiol. 21: 913-924.

Khvorova, A., Chary, V.K., Hilbert, D.W., and Piggot, P.J. 2000. The chromosomal location of the Bacillus subtilis sporulation gene spoIIR is important for its function. J. Bacteriol. 182: 4425-4429.

Kumar, N.M. and Gilula, N.B. 1996. The gap junction communication channel. Cell 84: 381-388.

Li, Z. and Piggot, P.J. 2001. Development of a two-part transcription probe to determine the completeness of temporal and spatial compartmentalization of gene expression during bacterial development. Proc. Natl. Acad. Sci. 98: 1253812543.

Londoño-Vallejo, J.A., Frehel, C., and Stragier, P. 1997. SpoIIQ, a forespore-expressed gene required for engulfment in Bacillus subtilis. Mol. Microbiol. 24: 29-39.

Marquis, K.A., Burton, B.M., Nollmann, M., Ptacin, J.L., Bustamante, C., Ben-Yehuda, S., and Rudner, D.Z. 2008. SpoIIIE strips proteins off the DNA during chromosome translocation. Genes \& Dev. 22: 1786-1795.

Meisner, J., Wang, X., Serrano, M., Henriques, A.O., and Moran Jr., C.P. 2008. A channel connecting the mother cell and forespore during bacterial endospore formation. Proc. Natl. Acad. Sci. 105: 15100-15105.

Nicholson, W.L. and Setlow, P. 1990. Sporulation, germination, and outgrowth. In Molecular biological methods for Bacillus (eds. C.R. Harwood and S.M. Cutting), pp. 391-450. John Wiley \& Sons, New York.

Odintsov, S.G., Sabala, I., Marcyjaniak, M., and Bochtler, M. 2004. Latent LytM at 1.3A resolution. J. Mol. Biol. 335: 775-785.

Pogliano, J., Osborne, N., Sharp, M.D., Abanes-De Mello, A., Perez, A., Sun, Y.L., and Pogliano, K. 1999. A vital stain for studying membrane dynamics in bacteria: A novel mechanism controlling septation during Bacillus subtilis sporulation. Mol. Microbiol. 31: 1149-1159.

Ragumani, S., Kumaran, D., Burley, S.K., and Swaminathan, S. 2008. Crystal structure of a putative lysostaphin peptidase from Vibrio cholerae. Proteins 72: 1096-1103.

Rawlings, N.D., Morton, F.R., Kok, C.Y., Kong, J., and Barrett, A.J. 2008. MEROPS: The peptidase database. Nucleic Acids Res. 36: D320-D325. doi: 10.1093/nar/gkm954.

Robinson, D.N. and Cooley, L. 1996. Stable intercellular bridges in development: The cytoskeleton lining the tunnel. Trends Cell Biol. 6: 474-479.

Rudner, D.Z. and Losick, R. 2001. Morphological coupling in development: Lessons from prokaryotes. Dev. Cell 1: 733-742.

Schaeffer, P., Millet, J., and Aubert, J.P. 1965. Catabolic repression of bacterial sporulation. Proc. Natl. Acad. Sci. 54: 704-711.
Serrano, M., Neves, A., Soares, C.M., Moran Jr., C.P., and Henriques, A.O. 2004. Role of the anti- $\sigma$ factor SpoIIAB in regulation of $\sigma^{\mathrm{G}}$ during Bacillus subtilis sporulation. I. Bacteriol. 186: 4000-4013.

Smith, T.J., Blackman, S.A., and Foster, S.J. 2000. Autolysins of Bacillus subtilis: Multiple enzymes with multiple functions. Microbiology 146: 249-262.

Sterlini, J.M. and Mandelstam, J. 1969. Commitment to sporulation in Bacillus subtilis and its relationship to development of actinomycin resistance. Biochem. J. 113: 29-37.

Sun, D., Fajardo-Cavazos, P., Sussman, M.D., Tovar-Rojo, F., Cabrera-Martinez, R.M., and Setlow, P. 1991. Effect of chromosome location of Bacillus subtilis forespore genes on their spo gene dependence and transcription by $\sigma^{\mathrm{F}}$ : Identification of features of good $\sigma^{\mathrm{F}}$-dependent promoters. $J$. Bacteriol. 173: 7867-7874.

Sun, Y.L., Sharp, M.D., and Pogliano, K. 2000. A dispensable role for forespore-specific gene expression in engulfment of the forespore during sporulation of Bacillus subtilis. J. Bacteriol. 182: 2919-2927.

Wu, L.J. and Errington, J. 1998. Use of asymmetric cell division and spoIIIE mutants to probe chromosome orientation and organization in Bacillus subtilis. Mol. Microbiol. 27: 777786.

Youngman, P., Perkins, J.B., and Losick, R. 1984. Construction of a cloning site near one end of Tn917 into which foreign DNA may be inserted without affecting transposition in Bacillus subtilis or expression of the transposon-borne erm gene. Plasmid 12: 1-9. 


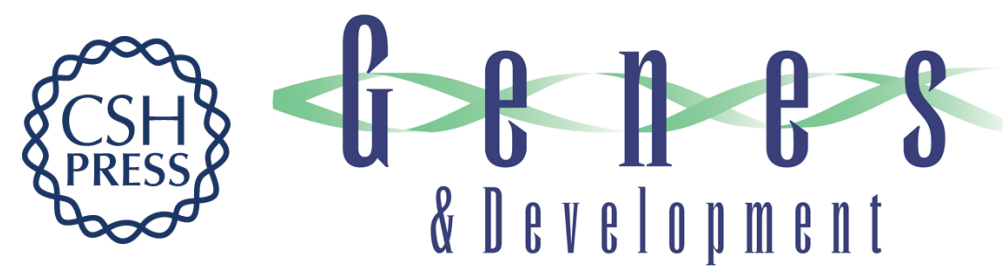

\section{A feeding tube model for activation of a cell-specific transcription factor during sporulation in Bacillus subtilis}

Amy H. Camp and Richard Losick

Genes Dev. 2009, 23:

Access the most recent version at doi:10.1101/gad.1781709

\section{Supplemental http://genesdev.cshlp.org/content/suppl/2009/04/16/23.8.1014.DC1 \\ Material}

Related Content

References

\section{License}

Email Alerting

Service
This article cites 38 articles, 18 of which can be accessed free at:

http://genesdev.cshlp.org/content/23/8/1014.full.html\#ref-list-1

Articles cited in:

http://genesdev.cshlp.org/content/23/8/1014.full.html\#related-urls

A Spores Lifeline

Annalisa M. VanHook

Sci. Signal. April , 2009 2: ec144

Receive free email alerts when new articles cite this article - sign up in the box at the top right corner of the article or click here.

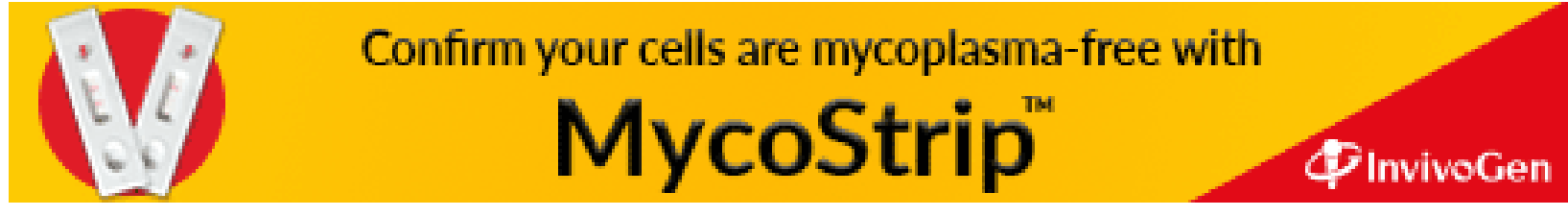

